\title{
For-profit policies and equitable access to antiretroviral drugs in resource-limited countries
}

\author{
Daniele Dionisio', \\ Arun Kumar Khanna, \\ Stavros Nicolaou, \\ Vijaya Raghavan, \\ Sandeep Juneja, \\ Aloka Sengupta \& \\ Daniela Messeri \\ ${ }^{\dagger}$ Author for correspondence \\ Access to Drugs: International \\ Policies - CLIA (Italian \\ Network for International \\ Fight against AIDS), \\ Member, Working Group \\ on AIDS (Decentralized \\ Cooperation of Tuscany \\ Region), \\ and, \\ Director, Infectious Diseases \\ Division, Pistoia Hospital, \\ Piazza Giovanni XXIII 1, \\ Pistoia, Italy \\ Tel.: +390573 352 324; \\ Fax: +390573352 309; \\ d.dionisio@usl3.toscana.it
}

Keywords: antiretroviral drugs, equitable access, for-profit policies, resource-limited countries

future, part of fso
medicine

\begin{abstract}
Unaffordable prices continue to obstruct access to antiretroviral drugs in incomeconstrained countries. This article explores the fitness of a multi-pronged, incentive-bound, WHO-mediated voluntary license strategy for attuning research, innovation, profit and equitable access to antiretrovirals in under-served markets. The potential of the model was investigated by examining: the predictable effect on current regulatory practices (traderelated aspects of intellectual property rights (TRIPS) and TRIPS-plus measures); the expected benefits, either in terms of equity or safeguarding of the generic and brand name manufacturer's interests; the interplay dynamics with drug trading policies of deeply concerned countries (China, India, countries in the EU, USA, Brazil, South Africa and Thailand); and the suitability for helping plants for generic antiretrovirals, including home plants in sub-Saharan Africa, undertake research and development partnerships encompassing innovation, technological catch-up, exploitation of TRIPS flexibilities, as well as raised marketing power and an increase in domestic employment. The explored strategy, although far from being the ideal solution, looks like it would be reliable to help expand equitable and sustainable access to appropriate antiretrovirals in resource-limited populations, as long as it entwines with the WHO's brokerage. It should also boost know-how, technology transfer, innovation, research and development, as well as national industry plant development and penetration of the wealthy and under-served markets by generic drug enterprises.
\end{abstract}

\section{For-profit policies still disregard the right to health}

There is increased skepticism regarding the fulfillment of pledges to secure universal access to antiretroviral (ARV) treatments by $2010[101,102]$. Unaffordable drug prices still obstruct access in income-constrained countries, while challenges are complicated by the enforcement of traderelated aspects of intellectual property rights (TRIPS) inside the World Trade Organization (WTO) (Table 1) [103,104]. Patent rules, along with exacerbated data exclusivity (Box 1), hamper the development of any new generic ARV formulation containing drugs with an exclusive status [1]. In addition, patent protection, by eliminating competition, causes a large increase in drug prices. For newer ARVs, this will be crucial once first-line formulations fail [2-5,105]; this is clearly a worrisome situation even though TRIPS rules encompass flexibilities (also including voluntary licenses [VLs] and compulsory licenses [CLs]) to help poorer populations equitably access low-priced ARVs (Table 1).

Again, unceasing pressure by the European Union (EU), Japan and the USA on the World Intellectual Property Organization (WIPO) towards global harmonization of patent laws could allow less autonomy in national decision-making regarding patents and increase the number of medicines that are too expensive for resource-limited countries [106].

Worryingly, evidence is available that Europe is too enmeshed in intellectual property (IP) protection to quickly approve the WTO's 6 December 2005 amendment, which would make a waiver inside WTO's 30 August 2003 decision to help countries insufficient in ARV drug manufacturing permanent (Table 1). Delayed endorsement of the amendment by the EU Parliament on the 24 October 2007 is coupled with a recent appeal by some members that Europe stops seeking WTO-plus IP drug protection in bilateral and regional trade transactions with resource-limited countries [107]. In addition, there is concern that the European Commission and member states will not be able to meet EU Parliament requests, first, to commit funding for both drug-related technology transfer and drug development for neglected diseases in the developing world; second, to play a more active role inside the WHO Intergovernmental Working Group (IGWG) on public health, innovation and IP; and third, to provide political support to governments seeking ways to make essential drugs available in their public health programs. 


\section{Table 1. TRIPS regulatory terms and dates for patent status of drugs.}

\section{Regulatory term}

Patent

TRIPS

Drugs invented before 1995

1995-2005 'mailbox' drugs

Post-2005 drugs

Dates for LDCS

Doha declaration

(14 November 2001)

Compulsory licensing

Voluntary licensing

Decision August 30, 2003

Parallel importation

Bolar exception

Data exclusivity

\section{Patent status}

A 20-year warranty securing the inventor exclusive rights on the overall drug production and marketing aspects. When countries signed up to the WTO they agreed to protect the patent rights of corporations selling drugs within their boundaries.

WTO agreement (1994) to the safeguard of IPRs around the world. It protects companies by stopping anyone from copying their products for at least.20 years.

No need for patent protection by a WTO member state if drugs were not patented before 1995 (i.e., before TRIPS came into force).

Refers to drugs invented in the period 1995-2005 (including second-line ARVs) for which WTO members that did not recognize drug patents before 1995 were offered diversified time limits to become TRIPS-compliant. Transitional countries have to hold patent applications on these drugs in a so-called mailbox and secure patent applicants EMRs for 5 years once the drug was in the mailbox and registration was made by the national drug regulatory authority.

All WTO members, with exception of LDCs, are requested to be TRIPS compliant.

LDCs had to become TRIPS-compliant by 2006 but, if national legislation was consistently amended, they are exempted from accepting patent protections and TRIPS enforcement until 2016. Aside from this flexibility, even LDCs have to issue compulsory licenses (see below) for importing copies of drugs already patented in pre-TRIPS domestic law.

Stated that each WTO member has the right to use TRIPS-encompassed flexibilities (which include compulsory and voluntary licenses) to secure universal access to drugs in the face of a public health need.

When a poor country government is allowed to manufacture domestically or to import copies of patented drugs at prices much cheaper than those imposed by the patent holder and without his consent. Both importing and exporting countries need to have enabling legislation in place (a corresponding CL for export has to be issued by the exporting country). Prior negotiation with the patent owner for a VL first is required unless for situations including extreme health crisis and not-for-profit government use. Payment of a royalty to the patent owner is encompassed by $C L$ rules.

Agreement negotiated with the patent's owner for manufacturing and marketing. Notwithstanding royalty rates imposition on generic firms, these licenses only imply straightforward agreements between companies; they do not require changes in national legislation, while including nonexclusivity, openings towards technology transfer, access to owner's data for branded drugs, as well as permission for export.

Allows nonmanufacturing countries to issue a $C L$ to import a generic version of a particular medicine based on a CL for export issued by the exporting country government. Declaration by the nonmanufacturing country of insufficiency in manufacturing the specific drug is required. WTO amendment approved on 6 December 2005 made the Decision permanent, based on two-thirds of WTO members ratifying it by December 2007 [141]. On 23 October 2007 the deadline was postponed to the end of 2009.

Importing of fairly priced patented drugs for which the rights of the patent owner have been exhausted by the first sale.

Permission to a generic firm for copying and registering a patented medicine before patent expiry. It could exceptionally be applied only if the normal rights of the patent holder are pledged.

Data protection against unfair commercial use only (but 5- and 8-year protection have been respectively requested by the USA and Europe).

ARV: Antiretroviral; CL: Compulsory licensing; EMRs: Exclusive marketing rights; IPRs: Intellectual property rights; LDCs: Least-developed countries; TRIPS: Trade-related aspects of intellectual property rights; VL: Voluntary licensing; WTO: World Trade Organization.

Nonetheless, some optimism should arise from the resolution on 'Public Health, Innovation and Intellectual Property' adopted on 23 May 2007 at the 60th WHO's World Health Assembly [108]. Among other points, the resolution requested the
WHO Director-General to help develop proposals on "... a range of incentive mechanisms including also addressing the linkage between the cost of research and development $(\mathrm{R} \& \mathrm{D})$ and the prices of medicines..." and to provide "...upon request, 


\section{Box 1. Exacerbated data exclusivity.}

- Term refers to a practice that temporarily bars registration files of an originator from being used to register the generic copy of a brand-name medicine. As long as a fixed time period ( 5 years in the USA and 8 years in Europe), Drug Regulatory Authorities are prevented from registering such generic equivalents unless the generic producer has carried out independently the required safety and efficacy tests, or bilateral agreements encompassing VL use (Table 1) have been undertaken.

- Data exclusivity impact consists of barring CL use (Table 1) until the expiry of data exclusivity itself and, mainly, in securing research-based companies a monopoly period in countries agreeing to data exclusivity even when a medicine is not patented in the specified country.

- This practice goes far beyond the WTO's request for data protection against unfair commercial use only (Table 1).

CL: Compulsory licensing; VL: Voluntary licensing; WTO: World Trade Organization.

in collaboration with other competent international organizations, technical and policy support to countries that intend to make use of the flexibilities contained in the agreement on TradeRelated Aspects of Intellectual Property Rights and other international agreements in order to promote access to pharmaceutical products...”.

Regrettably, pharmaceutical industry, represented by the International Federation of Pharmaceutical Manufacturers and Associations (IFPMA) disagreed with the resolution, attuning with a US disassociation statement [109].

However, the adopted resolution would suggest a key role for the $\mathrm{WHO}$ as broker and promoter in North-South and South-South negotiations wherein TRIPS flexibilities and incentives to scale-up equitable access to life-saving drugs are to be tackled.

Intriguingly, fulfillment of these favorable prospects will depend substantially on the drug trading directions of China, India, Brazil, South Africa and Thailand, as well as on measures to effectively offset US drug policy choices.

\section{India \& China's way forward with TRIPS management}

China applied TRIPS in 2002, while India did so on 1 January 2005. Overall, industrial plants of both countries supply most of their home needs while exporting high volumes of drugs to under-served markets. Chinese and Indian firms are increasingly becoming involved with multinational (not only health sector) industries in manufacturing and $\mathrm{R} \& \mathrm{D}$ partnerships including nanotechnology, robotics, as well as bioinformatics and genomics [110]. China and India have entwined interests with researchbased corporations to support their risky forays into the major world markets. In addition, the number of patent applications from China and India filed at the US Patent Office has been rising rapidly [110]. China and, to a lesser extent, India, are, moreover, the major suppliers of active pharmaceutical ingredients (APIs) for ARVs to the developed and developing world [111]. This gives both countries power in influencing ARV drug price evolution. Indeed, as APIs represent the largest component of direct manufacturing costs (55-99\%) [6], significant decreases in ARV prices will depend on a concomitant decrease in API price.

\section{India: final strategy pending}

Indian patent law causes uncertainty in keeping ARVs affordable [112]. 1995-2005 'mailbox' medicines (Table 1) and newer drugs whose generic versions are not yet made by Indian firms can only be sold as branded originals, unless CLs or straightforward agreements with the patent holders are obtained. Conversely, Indian companies currently producing generic versions of medicines for which patent applications were submitted prior to 1 January 2005 are allowed to carry on if they have made a 'significant' investment and pay a royalty to the patent owner [112]. This suggests that, without incentives, the prices of 'generics' produced under such a royalty will only increase, making these drugs inaccessible to resource-limited countries. It also suggests that CLs will hardly be issued by the Indian government because of threats to keeping partnerships with researchbased enterprises and risks of retaliation by wealthy country governments. In policy terms, the Indian government seems to be reluctant to damage the interests of US-based pharmaceutical companies, also due to the fact that India depends on the USA as far as mutual interests in the strategy balance with China and Pakistan are concerned.

\section{China: how to channel escalation?}

China could become the ARV factory for the developing world because of its cheap APIs and industrial scale-up, coupled with steady penetration of under-served markets [7,113,114]. Chinese producers are already making first-line ARV formulations, as well as raw materials for first- and second-line ARVs [7]. Regrettably, while no Chinese ARV drugs have been WHO prequalified to date, China is under pressure due to its weak pursuance of TRIPS [7,115]. Nonetheless, the Chinese government could possibly be attracted by TRIPS-bound VLs for the following needs: 
- Technological catch-up while aiming to compete with multinational drug corporations

- Trustworthy relationships with research-based companies

- Enhanced domestic ARV production including fixed-dose combinations (FDCs) and pediatric formulations, both of which are not yet produced in China

- Sustainable self-sufficiency in pharmaceutical manufacturing, breaking away from price fluctuations by foreign enterprises

Overall, the VL model would improve the performance of China's 'Four Frees, One Care' policy in that it would be expected to help expand domestic access to free ARVs.

\section{Implications from US drug policy choices}

For-equity strategies should be able to offset US policy currently torn among:

- Defense of 'brand name' ('free-trade agreements' with coercive TRIPS-plus clauses are mushrooming) [8]

- 'Shy' acknowledgment of generic ARVs, with no reliability for routine use in the US President's Emergency Plan for AIDS Relief (PEPFAR)

- Incidental opening to generic ARVs from US strategic agreements on the international chessboard; in fact, on 2 March 2006, USA-India signed a 'civil nuclear power' agreement [116], which did result in PEPFAR exploitation of Indian ARVs [117-119]

Just after the agreement on reforms was reached at the WIPO Meeting on Development (Geneva, Switzerland, 11-15 June 2007), the USA stated that, whilst WIPO's proposals were reinforcing WIPO's commitment to the needs of developing countries, it was clear WIPO's mandate to promote IP protection worldwide [120]. Moreover, as far as the WHO's IGWG plan on pharmaceutical innovation is concerned, the USA has already stated that it would not support any new funding mechanism and that topics present in the innovation plan, such as TRIPS flexibilities and bilateral trade agreements, would be more appropriate to the scope and mandate of the WTO and WIPO [121]. Subsequently, when the resolution on pharmaceutical innovation was adopted by WHO members at the 60th World Health Assembly, the USA disassociated itself [109]. It is also to be expected that current debate in the USA on a move to make free-trade agreement language closer in line with the WTO-endorsed Doha Declaration (Table 1) will probably be unsuccessful or result in no more than cosmetic changes [122].

\section{Brazil, South Africa \& Thailand's directions}

Forecasts suggest that costs for ARV therapy in Brazil will continue to climb unless the country violates patents or negotiates better deals with drug multinationals [9]. In 1996, Brazil enforced the TRIPS agreement: accordingly; Brazil could produce ARVs patented before, but not improved or new drugs that had come to market subsequently. Brazil has the technical capacity to produce all new ARVs, but CLs have very rarely been issued to date (including for Merck's efavirenz on May 2007) because of fear of damaging international, mainly US, trade relations. Currently, Brazil spends $80 \%$ of its $\$ 445$ million annual budget on imported ARVs. If the government instead made ARVs at the state-owned Farmanguinhos industry, the country would save money [9]. Also, the costs of currently homemade ARVs would be reduced if Brazil started to produce APIs instead of purchasing them from India and China.

It seems that South Africa is currently gaining ground regarding national plans to boost HIV prevention and treatment [10]. Presently, most ARVs at public clinics are paid for by the government, but international organizations and donors pay for costs at many private facilities, and medical insurance covers other individuals. Meanwhile, the South African Aspen company continues to manufacture most generic ARVs while signing innovative VL-based deals with drug multinationals [123,124].

The Thai government issued a CL against Abbott's heath-labile lopinavir/ $r$ in January 2007; 2 months after the government issued a CL for Merck's efavirenz. The country will import the corresponding generics from India until production by the state-owned Government Pharmaceutical Organization comes on line [125]. Follow-up is needed to verify the sustainability of the Thai CL policy. Negotiations between the government and drug companies are still continuing. In the meantime, the US Trade Representative's Office placed Thailand on its Priority Watch List on 30 April 2007 [126]. In May, the Thai Minister of Public Health announced that Brazil and Thailand would sign a cooperation agreement on health development [127]. 
Rationale for setting-up incentive-bound VL strategies

Compulsory licensing has brought treatment with newer ARVs within reach in the developing world, but has resulted in strong pressure and sometimes retaliation from industries and governments in wealthy countries. Therefore, less risky solutions to maximize sustainable access to ARV drugs in those settings should also be looked for. What matters for governments and the pharmaceutical industry in resource-limited countries is to finance ways agreed upon by all counterparts to make these medicines (including newer ones) stably affordable and accessible to the worst-off financially.

Current dynamics among concerned parties could possibly help predict trends, and allow appropriate working strategies to be set up.

On a world perspective, increasingly multiplying South-South partnerships [128-130] and enhancing $\mathrm{R} \& \mathrm{D}$ leadership of multinational research-based corporations [11,131] are concurrently emerging as leading phenomena in the ARV drug production and marketing sector. Together, these dynamics entail a number of consequences that may be worth in-depth analysis.

New South-South partnerships addressing the building and output of malarial, TB and ARV drug plants (also as wide Southern Africa regional companies to become cost-effective and stronger in resisting pressures by drug multinationals and wealthy country governments) were recently signed in Africa, or are currently underway, between country governments (i.e., Mozambique-Zimbabwe, Mozambique-Brazil) or generic drug companies (i.e., Ugandan Quality Chemicals-Indian Cipla Pharmaceuticals Ltd) [128-130]. They fall into the African Union self-sufficiency plans [132] and add to the already working examples of country-owned drug plants in other African countries [5]. These partnerships strengthen generic drug companys' competitiveness against the multinationals. In-depth forecasts from South-South partnerships suggest the erosion of both profits and overseas markets for brand-name enterprises, while, for the stronger counterpart in transactions (leading generic industry or developing country government) the advantages would include market expansion encompassing royalties, revenues from selling APIs, as well as further entering the receiving country through wider-sector trade opportunities. Again, for the other counterpart these partnerships would represent self-sufficiency in pharmaceutical manufacturing, escape from dependence on countries guilty of 'colonial past', sustained drug supply to the home market, an increase in domestic employment, as well as discounts for the purchase of APIs.

On the other side, research-based drug multinationals continue with unrivalled $\mathrm{R} \& \mathrm{D}$ leadership and strong policy support by the USA and Europe. As a consequence, only research-based corporations would be capable of new drugs discovery in a medium- to long-term time period. This implies that patent rights exploitation, control of prices, attraction power and ongoing prestige on the world market will be kept by them indefinitely. This links with exceeding R \& D investments made recently in China (Shanghai) and Singapore (Biopolis) by big pharmaceutical companies (i.e., Novartis, Merck, AstraZeneca, Roche, Abbott, Pfizer, Glaxo, Aventis, Schering and Wyeth) [11,131]. Mutual trade interests there secure brand-name corporations substantial incentives such as high salaries for research staffs, low cost of local manpower, partial refunding for research expenditures, as well as fiscal exemptions and a favorable legal environment.

On the whole, awareness of all the scenarios above, coupled with TRIPS and TRIPS-plus hindering obligations, should definitely spur generic drug manufacturers into boosting innovation, aiming at new drug discovery. This end result would add prestige and allow them to more easily gain western markets while enhancing competition with brand-name counterparts. Again, this would allow them to enjoy the advantages of patent protection adoption while pushing ahead more profitable North-South partnerships [133].

Based on this information, why should generic manufacturers insist on risky and poorly profitable CLs rather than fuelling multipronged VL deals with brand-name industry as far as exploitation of entwined know-how, training and technology transfer for the production of new ARVs? Achievement of high-level performance through these opportunities would help generic companies save time while looking for innovation standards.

Conversely, threats to their profits by South-South partnerships and CL issuing are really expected to push multinational brandname corporations towards more equitably harmonized VL transactions with generic competitors. Regarding this, the growing potential of Indian and Chinese plants (enhanced by the November 2006 China-India signed trade partnership) would predictably catalyze more 
profitable VL agreements for developing country firms as a whole. Ultimately, these agreements would secure all counterparts sustained advantages, while maintaining the leadership of brandname corporations and delaying wealthy market forays by generic firms. Working examples of already signed VL agreements are available:

- The Bristol-Myers Squibb (BMS) agreement with Aspen Pharmacare and Emcure Ltd to manufacture and sell the protease inhibitor (PI) atazanavir in sub-Saharan Africa and India, respectively (February 2006): a royaltyfree license to operate under relevant patents was encompassed, along with transfer to Aspen and Emcure of BMS technical knowhow related to the manufacturing, testing, packaging, storage and handling of the API and the finished dosage form of atazanavir. BMS provision of technical training both at its manufacturing facilities and at Aspen's and Emcure's facilities in South Africa and India was also included, along with support to the two companies for regulatory filings [123];

- The Johnson \& Johnson subsidiary, Tibotec Pharmaceuticals, agreement with Aspen Pharmacare to package and cheaply distribute the new PI darunavir in Sub-Saharan Africa (April 2007) [124];

- The Roche agreements with the Addis Pharmaceutical Factory (Ethiopia) and Varichem Pharmaceuticals (Zimbabwe) for ARV production training (May 2007): the two African companies will be provided with no-cost technical training and guidance to manufacture generic ARVs based on the processes used to develop Roche's second-line ARV saquinavir. Roche staff will work onsite at the manufacturing facilities in Ethiopia and Zimbabwe and from the company's headquarters in Switzerland. Generic saquinavir marketing will not be allowed outside Sub-Saharan Africa and least developed countries. A total of 32 manufacturers in 15 eligible countries (including Ghana, Kenya, Nigeria and Zimbabwe) have expressed interest in participating in the initiative [134].

The thoughts expressed so far also underscore the need for setting up country-owned plants for generic ARVs in sub-Saharan Africa [4,132]. Indeed, home plants would add strength for negotiating profitable VLs encompassing equitably expanded ARV drug access. The industrial potential will likely rely on drawing branded drug producers into more flexible agreements securing mutual advantages. Under such a scenario, China's cheapest APIs could serve as a key source for the expansion of sub-Saharan plants. This is consistent with exceeding China's interests in Africa by bilateral agreements already signed, or currently underway, with many African countries and encompassing trade, energy supply, investments, as well as infrastructure and health cooperation [113].

Overall, the dynamics highlighted here may explain the generic and brand-name industry's confluence of interest towards harmonized VL negotiations for the manufacturing and marketing of affordable ARVs. These agreements should include combination incentives and the WHO's brokerage to secure as fairly as possible both low-priced drugs and expanded access to ARVs. This model would promote and enhance:

- Sustainable and equitable access to life-saving treatments

- Domestic employment and national and/or international market increases

- $\mathrm{R} \& \mathrm{D}$ and international standard innovation plans

\section{VLs: vantage points from generic industry Arun Kumar Khanna (Emcure Pharmaceuticals Ltd, India)}

Generic manufacturers have played a major role in enhancing access to quality ARVs to the needy in the developing world. Entry of generic players has not only reduced costs but also helped in increasing usage leading to economies of scale and further bringing prices down. Challenges that lie ahead include providing a vital secondline medication, which is still under patent protection by their innovators.

VLs enable local manufacturers to produce and sell generic versions of innovator's products. Thus VLs, by safeguarding the interests of the innovator, would help tackle to a greater extent some of the important issues of affordability, availability and accessibility of quality ARVs, especially in developing nations. Some of the multinational pharmaceutical companies such as Glaxo SmithKline, Boehringer Ingelheim, BMS and Gilead, as part of their global access program and/or corporate social responsibility initiatives, have extended VLs to generic manufacturers. VLs can be a rational approach against the CLs by respecting IP rights - wherein the interests of the innovator are protected. 
Voluntary licensing could be exclusive or nonexclusive, come with a fee or be free to a generic manufacturer or else attract royalties. Multinational companies have adopted either or some of these forms of VL. In any case, VLs enable generic manufacturers to develop the product at a lower cost than the innovator without compromising drug efficacy. Once the innovator extends technology transfer to the competent generic player, they can even procure the API from the licensed generic manufacturer for lowering the cost of their branded formulations. In some cases, they can also procure finished formulations from the generic formulator for reduction in their costing.

However, the generic manufacturers who benefit from VLs have to ensure that the product is as per the standards specified with the proprietary drug and have capacities to provide longterm supply of medicines. Also, the onus is on the generic manufacturer to prevent diversion of these medicines to the markets that are not designated as per the VL.

As under VL with technology transfer the generic manufacturer needs to conduct bioequivalence of the product for regulatory approvals, simplifying these procedures and waivers on certain processes will help the generic manufacturer to further reduce the cost, which will ultimately benefit the final consumer.

Another solution is to establish centralized procurement of ARVs by global agencies. This requires a massive public-private partnership along with coalition of governing bodies of various developed countries. By extending incentives to the innovators in terms of $\mathrm{R} \& \mathrm{D}$ tax credits, public sector funding, prize funds etc., they can urge innovators to extend profitable VLs to generic manufacturers. As a whole, this will have a double impact on reducing the cost for global procurement: first, the generic player will be able to develop the product at reduced cost than the innovator, and second, centralized purchases provide economies of scale that will further help the generic player bring down the cost.

\section{Stavros Nicolaou (Aspen Pharmacare Holdings, South Africa)}

Africa's largest pharmaceutical manufacturer, Aspen Pharmacare decided 7 years ago to enter the ARV manufacturing market and has subsequently become the leading supplier of ARVs in sub-Saharan Africa. Aspen's decision, which requires security in secure supply chain and a stable and consistent supply, was prefaced under four imperatives. These included sufficient capacity for finished dose manufacture, sustainable and stable supply of APIs, a comprehensive and continuous pipeline of ARV products and, importantly in the context of this paper, assurance that Aspen did not enter into any legal minefield or potential disruption of supply due to IP infringement.

The IP consideration was the initial one, but also a very critical one. South Africa has strong IP laws and is a signatory to the TRIPS agreement and other multilateral trade agreements. Aspen was acutely aware of South Africa's multilateral trade obligations and also some of the provisions contained in, for example, article 31f of TRIPS [104]. Aspen, however, felt that the provisions contained in article 31f, the discussions in the development rounds of DOHA, and CL provisions in the case of public health emergencies were neither practical, nor were they conducive to expediting access to ARV treatment in South Africa and the sub-Saharan region. It also felt that compelling mandatory or compulsory options merely fuelled tensions, which would probably ultimately not be in the best interest of patients. Learning from the South African periand post-democratic consultation process, Aspen felt that engaging the IP holders and pursuing VLs, rather than CLs was the best way to proceed. This approach yielded the required outcomes and created a win-win situation for all the stakeholders concerned, including patients, civil society, South African Government, the R \& Dbased industry and Aspen as a local manufacturer. In a nutshell, the VL route enhanced the access of patent protected product for public health emergencies, did not undermine the multilateral patent system or any of South Africa's multilateral trade obligations and developed a local capability in Africa.

This VL formula has a number of spin-off benefits, such as allowing for operational synergies between multinationals and local producers, retains and creates new skills, provides new technologies, makes these products more affordable and above all provides hope to countless AIDS patients. It is instructive that this VL model has evolved over time, from the initial rudimentary immunity of suite agreements, to that of fully fledged license, technology transfer, manufacturing, capital expenditure subsidy and distribution agreements, with the latest technology transfers, by, for example, BMS and Eli Lilly, involving transfer at the level of vertical integration. 


\section{Vijaya Raghavan \& Sandeep Juneja (Ranbaxy Ltd, India)}

In this age of ever-stronger patent laws, one of the key apprehensions that developing and least-developed ( $\mathrm{D} \& \mathrm{LD}$ ) countries have is that whether stronger patents promote innovation or not, they will certainly end up limiting, if not completely denying, access to quality medicine. Access is determined by both cost and availability.

In order for medicines to be truly accessible to patients in D \& LD countries, availability at an affordable cost must be ensured. Ensuring continued access to medicines is the most important consideration. If that reality is understood, then it becomes very clear that VLs are the way to go. In fact, a sincere but failed attempt at obtaining a $\mathrm{VL}$ is a necessary requirement to apply for a CL in most countries, except in cases of national emergencies, when the government can override such requirements. The reasons why VLs should be the preferred route are clear:

- VLs are quicker to obtain and thus help us bring drugs to market quickly. The CL process is longer and more time-consuming: not in the best interests of the patients (and generic cos)

- There may be better clarity on operating boundary conditions in the VL process, as terms are clearly laid out between the two companies; in a CL things can be more ambiguous

- A VL is a win-win situation and usually far more amicable. It helps the licensor get some positive property right and public goodwill. On the contrary, a CL may mar relations between an originator and a country

- As VLs are normally subject to certain conditions, it provides the innovator company better control over distribution or even the cost

- As a VL is between two parties, the room for governments to intervene is drastically reduced

\section{Aloka Sengupta (Strides Arcolab Ltd, India)}

The availability of affordable, quality, multisource, front-line ARVs has changed the profile of HIV/AIDS from a catastrophic disease to a manageable chronic one. This has been possible due to the single-minded efforts of UN organizations, activists and cost-effective innovations in technology from Indian manufacturers. Currently, the cost of therapy per patient is approaching US\$100 per year for selected front-line ARVs in the least developed countries.
However, millions of HIV-positive people still do not have affordable access to treatment, particularly in 'non-least-developed'/medium income countries. The situation is even more worrisome with regard to second-line treatment. The major issues that are impeding acceleration of access to ARV treatment may be summarized as follows:

- IP regimes applicable to newer and secondline ARVs: 'non-least-developed' countries that are WTO members will be obligated to grant patents on pharmaceutical products post-2005

- Existing patents in medium-income/developing countries: Brazil and Thailand are examples where CLs had to be invoked to make newer ARVs affordable

- Nonproducing countries are probably in the worst situation, as CLs usually mandate that drugs be supplied predominantly to the domestic markets. This may create bottle necks in export of newer products to nonproducing countries

It should be noted that the dominant suppliers of affordable quality generic ARVs are based in India. Post-enactment of new patent laws in February 2005, the role of India as the key global source of inexpensive ARVs is fraught with uncertainties. Resolution of legal challenges and disputes over patentability of new inventions will be time-consuming and expensive. The HIV population can ill afford to wait. The only viable solution for affordable access to ARVs in medium-income countries and to newer and second-line ARVs in least developed and medium-income countries is through VLs, preferably mediated by the WHO. High-quality VLs will facilitate the availability of multisource products at affordable prices and will promote technology transfer.

\section{Incentive-bound WHO-mediated VLs: a multipronged model for appropriate \& equitable long-term solutions}

VLs could be an attuning strategy to the overall scenarios presented here. Indeed, VLs only imply direct agreements between firms; they do not require changes in national legislation, while encompassing nonexclusivity, openings to technology transfer, access to owner's data, as well as consent for export (Table 1).

Understandably, VLs are far from being the ideal solution. In fact, the best mechanism for ensuring that prices of ARVs become as 
affordable as possible would be to manage for unrestrained competition by CLs. Replacing with a managed competition under VLs would represent no more than a second best. Unfortunately, pressures currently placed on the developing world by the governments of wealthy countries make the prospect of CLs being extensively adopted look unlikely.

A number of constraints limit VL model potentials. If a patent holder decides to grant a VL, they will use the control that IPs bring to determine what the licensee is allowed to do. Additionally, the licensee would likely be forbidden to compete with the brand-name company in their market but would be compelled to supplying a developing country market.

Nonetheless, VLs meet the interests of generic companies, allowing them to achieve technological catch-up to measure with research-based enterprises into the wealthy and under-served markets. VL-bound opportunities, rather than CL-bound copying, would better help attain this goal.

In addition, the VL model, as it does not hinder low-cost API provision by China and India to generic firms not producing APIs, would help generic firms continue domestic ARV manufacture. This would be crucial, as APIs for certain ARVs are still under patent in many countries: with no alternatives in place, this would restrict the market to very few suppliers and lead to high prices for these APIs and finished drugs [6]. Additionally, the VL model would counter IP restrictions enacted under TRIPS-plus agreements that might further limit the sources of APIs [6]. Furthermore, VL policy would help countries with no manufacturing capability import generic ARVs without undertaking hard CL-bound changes in national law (Table 1). Again, predictability of HIV resistance mutations in the developing world allows VLs to be assigned a spin-off linking in with urgency for newer ARVs [4].

As mentioned above, VL agreements could be expected to work at their best under the WHO's brokerage and combination incentives equipment. These incentives are awaited by governments and international players, which also include the Global Fund to Fight AIDS, TB and Malaria, the World Bank, the WHO, as well as UNAIDS and the Clinton Foundation. Again, these incentives must encompass funding to give generic manufacturers reasons for keeping prices low. Funding could even arise through securing the support of African governments to meet the Abuja Declaration commitment to set aside $15 \%$ of national Gross Domestic Product for health spending [135]. Full debt cancellation to poor countries would also help [136,137].

The UNITAID-International Drug Purchase Facility should also be assigned (thanks to complementarities with all institutions mentioned above) a special role to help the combination incentive strategy succeed [138]. Country governments could be allocated UNITAID revenues to finance fiscal relief to their generic companies. These revenues, again, could allow (as in the recently signed Clinton Foundation-UNITAID-Cipla and Matrix agreement) multiyear, large-volume purchasing programs with WHOprequalified generic drug companies to be negotiated by international players $[139,140]$.

In detail, the combination incentive strategy should comprise:

- Exclusive bulk purchasing of generic ARVs by international donors, based on acceptance of WHO prequalification. This would result in price reductions. The transparency enjoyed through WHO checks would make the model trustworthy;

- Fiscal relief to generic firms by country governments. Sources of tax allowance include: enhanced disbursement by donors, domestic expenditure priority reallocations, and debt relief savings from debt cancellation. The WHO and UNAIDS, following the acknowledgement of country pledges to channel debt relief savings towards tax allowances, should promote approval of debt cancellation while checking for pledge pursuance;

- WHO brokerage in VL negotiations with research-based corporations. This would maximize equitable access to drugs.

\section{Conclusion}

Incentive-bound VLs look likely to bring, through the WHO's brokerage [12], several opportunities to generic enterprises, while cutting prices and promoting equitable access to ARVs. The VL model explored here would allow generic manufacturers to overcome patent protection while not being barred by exacerbated data exclusivity that is associated with CL use (Box 1). Additionally, it would protect countries against the risk that the 6 December 2005 CLbound public health waiver might not be formally built into the TRIPS agreement; as of 28 November 2007, only 13 WTO member states had ratified the waiver, out of 151 asked to do so 
by December 2007 (Table 1) [141,142]. This failure may explain the recent WTO decision to postpone the deadline to the end of 2009 [143].

Overall, the suggested model appears to be a fitting formula for the present day, with some advantages over CLs [4,13,105]. Nonetheless, CL threat inside VL-based transactions is fruitful as it would bring patent owners to a more reasonable position and give generic firms stronger negotiation power.

\section{Future perspective}

This paper focuses on a multi-pronged strategy aimed at attuning the interests of all counterparts. A suitable strategy must be equipped to equitably affect current regulatory practices, while meeting the interests of the generic and brand-name manufacturers and, at the same time favoring for-equity dynamics with the drug trading policies of deeply concerned countries. Additionally, this strategy should be suitable for helping generic ARV plants, including home plants in sub-Saharan Africa, initiate and undertake $\mathrm{R} \& \mathrm{D}$ partnerships encompassing innovation, technological catch-up, exploitation of TRIPS flexibilities, as well as increasing marketing power and domestic employment. This strategy should include combination incentives and the WHO's brokerage to secure, as fairly as possible, both low-priced drugs and expanded access to ARVs.

Fulfillment of these favorable prospects will depend substantially on the policy choices of the European Union, USA, China, India, Brazil, South Africa and Thailand. The interplay and end results of these policies on a world perspective are not fully predictable at present.

\section{Financial \& competing interests disclosure}

The authors have no relevant affiliations or financial involvement with any organization or entity with a financial interest in or financial con-flict with the subject matter or materials discussed in the manuscript. This includes employment, consultancies, honoraria, stock ownership or options, expert testimony, grants or patents received or pending, royalties

Daniele Dionisio conceived, designed and wrote the paper. Arun Kumar Khanna, Stavros Nicolaou, Vijaya Raghavan, Sandeep Juneja and Aloka Sengupta authored the section "VLs: vantage points from generic industry". Daniela Messeri shared in draft preparation and data collection of the contribution by Daniele Dionisio and oversaw inner correspondence of the final contents. All authors participated in the overall interpretation, revision and harmonization of the whole paper.

\section{Bibliography}

Papers of special note have been highlighted as either of interest $(\bullet)$ or of considerable interest $(\bullet \bullet)$ to readers.

1. Correa CM: Implications of bilateral free trade agreements on access to medicines. Bull. World Health Organ. 84(5), 399-404 (2006).

•• Outstanding paper regarding knowledge and implications of bilateral free-trade agreements on access to medicines.

2. Kim JY, Gilks G: Scaling up treatment why we can't wait. N. Engl. J. Med. 353, 2392-2394 (2005).

3. New W: Rich and poor countries divided on patent treaty. Bull. World Health Organ. 84(5), 344-346 (2006).

4. Dionisio D, Gass R, McDermott P et al.: What strategies to boost production of affordable fixed-dose antiretroviral drug combinations for children in the developing world? Curr. HIV Res. 5(2), 155-187 (2007).

-. This joint paper cogently provides arguments for the immediate increase of production and development of fixed-dose combination ARVs for children.
5. Dionisio D, Cao Y, Hongzhou L, Kraisintu K, Messeri D: Affordable antiretroviral drugs for the under-served markets: how to expand equitable access against the backdrop of challenging scenarios? Curr. HIV Res. 4(1), 3-20 (2006).

6. Pinheiro E, Vasan A, Kim JY et al.: Examining the production costs of antiretroviral drugs. AIDS 20(13), 1745-1752 (2006).

7. Tanner JA: WTO TRIPS and its effect on the supply and development of medicines in China. Hong Kong Med. J. 12(1), 84-86 (2006).

8. Westerhaus M, Castro A: How do intellectual property law and international trade agreements affect access to antiretroviral therapy? PLoS Medicine 3(8), 1-7 (2006).

-• Outstanding paper focusing on the implications of intellectual property and trade agreements on access to antiretroviral drugs.

9. Cohen J: Brazil: ten years after. Science 313, 484-487 (2006).

10. South Africa’s AIDS plan: Nature 447(7140) (2007).
11. Stone $\mathrm{R}, \mathrm{Xin} \mathrm{H}$ : Chinese drug research: Novartis invests $\$ 100$ million in Shangai. Science 314, 1064-1065 (2006).

12. De Cock K, Grubb I: Towards universal access: WHO's role in HIV prevention, treatment and care. Bull. World Health Organ. 84(7) 506 (2006).

13. Friedman MA, Den Besten $\mathrm{H}$, Attaran A: Out-licensing: a practical approach for improvement of access to medicines in poor countries. Lancet 361 , 341-344 (2003).

\section{Websites}

101. Governments, donors falling short of goal to provide no-cost antiretroviral access. Kaiser Daily HIV/AIDS Report, 19 July 2007. www.kaisernetwork.org/Daily_reports/print _report.cfm?DR_ID=46326\&dr_cat

102. Global commitments to provide universal access to HIV/AIDS treatment will not be met at current pace. Kaiser Daily HIV/AIDS Report, 23 May 2007. www.kaisernetwork.org/Daily_reports/ print_report.cfm?DR_ID $=45088 \&$ dr_cat 
103. MSF report shows up to $500 \%$ price rise in HIV/AIDS drugs. MSF campaign for access to essential medicines. Médecins Sans Frontières, 23 July 2007. www.accessmed-msf.org/prod/publications. asp?scntid $=23720071050295 \&$ cont

104. Overview: the TRIPS Agreement. World Trade Organization (2005). www.wto.org/English/tratop_e/trips_e/intel 2_e.htm

105. Towards universal access: scaling up priority HIV/AIDS interventions in the health sector. WHO, UNAIDS, UNICEF, April 2007.

www.who.int/hiv/mediacentre/univeral_acc ess_progress_report_en.pdf

106. Sources and prices of selected medicines and diagnostics for people living with HIV/AIDS. UNAIDS/WHO/MSF, June 2005. www.accessmedmsf.org/documents/sources.pdf

107. European Parliament ratifies TRIPS amendment. ICTSD Bridges, 11(36) (2007). www.ictsd.org/weekly/07-10-24/story2.htm

108. "Public health, innovation and intellectual property” resolution adopted at WHO's sixtieth world health assembly WHO, Geneva, Switzerland, 23 May 2007. www.who.int/gb/ebwha/pdf_files/WHA60/ A60_R30-en.pdf

109. WHO remains flexible on drug access rules. Science and Development Network, 6 June 2007.

www.scidev.net/news/index.cfm?fuseaction= printarticle\&itemid $=3663$ \&langua...

110. Bale H: TRIPS flexibility and access to medicines - the case of new ARV medicines. Prince Mahidol Award Conference, 2 February 2007. www.ifpma.org/pdf/HB\%20PMAC\%20Th ailand\%2002Feb07.pdf

111. Grace C: The effect of changing intellectual property on pharmaceutical industry prospects in India and China: considerations for access to medicines. DFID Health Systems Resource Centre (2004).

www.dfidhealthrc.org/shared/know_the/pu blications.html\#access

112. Revised Patent Law www.patentoffice.nic.in/ipr/patent/patent_ 2005.pdf

113. China's African Policy, January 2006. www.fmprc.gov.cn/eng/zxxx/t230615.htm

114. Mwega FM: Africa's burgeoning trade relationship with China. Comment: Bridges (No. 2), 13-14 (2007). www.ictsd.org
115. WTO scrutinises China's trade policies. ICTSD Bridges 10(36) (2006). www.ictsd.org/weekly/06-1101/story4.htm

116. US, India clinch nuclear deal, call pact "historic". 2 March 2006. http://news.yahoo.com/s/afp/20060302/ts_ usindiabushnuclearpoliticsdeal

117. FDA grants tentative approval for Matrix's antiretroviral drug abacavir. Kaiser Daily HIV/AIDS Report, 12 April 2007.

www.kaisernetwork.org/daily_reports/rep_i ndex.cfm?DR_ID=44195

118. Strides Arcolab receives tentative FDA approval for efavirenz under PEPFAR Review Process. Kaiser Daily HIV/AIDS Report, 30 March 2007. www.kaisernetwork.org/Daily_reports/rep_ hiv_recent_rep.cfm?dr_cat $=1 \&$ show...

119. FDA grants Cipla tentative approval to produce generic pediatric antiretroviral for PEPFAR. Kaiser Daily HIV/AIDS Report, 14 August 2007.

www.kaisernetwork.org/daily_reports/print _report.cfm?DR_ID $=46849 \& d r \_c a t=1$

120. WIPO members agree on development agenda. ICTSD Bridges 11(22) (2007). www.ictsd.org/weekly/07-06-20/story1.htm

121. WHO members divided over plan for promoting pharmaceutical innovation. ICTSD Bridges, 11(14) (2007). www.ictsd.org/weekly/07-04-25/story3.htm

122. New trade agreement language to allow developing countries more flexibility in circumventing drug patents, other restrictions. Kaiser Daily HIV/AIDS Report, 22 June 2007. www.kaisernetwork.org/Daily_reports/print _report.cfm?DR_ID $=45751 \& d r \_c a t . .$.

123. Aspen and BMS conclude strategic ARV deal. 16 February 2006. www.sharedata.co.za/sens.asp?id=82577

124. Aspen Pharmacare, Tibotec enter agreement to distribute protease inhibitor Prezista in Sub-Saharan Africa.

Kaiser Daily HIV/AIDS Report, 10 April 2007. www.kaisernetwork.org/Daily_reports/print _report.cfm?DR_ID $=44130 \& d r \_c a t . .$.

125. Thailand authorises generic production of two more patented drugs. ICTSD Bridges 11(3) (2007). www.ictsd.org/weekly/07-01-31/story2.htm

126. US Trade Representative places Thailand on Priority Watch List in annual report. Medical News Today, 3 May 2007. www.medicalnewstoday.com/printerfriendly news.php?newsid=69507
127. WHO members adopt resolution on pharmaceutical innovation. ICTSD Bridges, 11(18) (2007). www.ictsd.org/weekly/07-05-23/story2.htm

128. Mozambican officials call on Southern African development community to create regional pharmaceutical company for antiretroviral production. Kaiser Daily HIV/AIDS Report, 1 June 2007. www.kaisernetwork.org/daily_reports/print _report.cfm?DR_ID=45282\&dr_cat

129. Brazil offers to provide technology, training for proposed pharmaceutical plant to produce HIV/AIDS, malaria drugs in Mozambique. Kaiser Daily HIV/AIDS Report, 30 May 2007.

www.kaisernetwork.org/daily_reports/print _report.cfm?DR_ID $=45221 \&$ dr_cat

130. Ugandan, Indian pharmaceutical manufacturers partner to produce low-cost antiretrovirals. Medical News Today, 10 April 2007.

www.medicalnewstoday.com/printerfriendly news. php?newsid $=67155$

131. Biopolis, a world-class Research Complex. Singapore's Agency for Science, Technology and Research. www.a-

star.edu.sg/astar/biopolis/index.do

132. Africa plans to produce own drugs, reduce reliance on West. Agence France Press, 11 April 2007.

http://news.yahoo.com/s/afp/20070411/hl_ afp/africanunionhealthdrugs_07041114245

133. Saini A: Making poor nations pay for drugs. New Scientist.com news service, 31 March 2007.

www.newscientist.com/article.ns?id=mg193 25972.800\&print=true

134. Roche signs agreements with Ethiopian, Zimbabwean pharmaceutical companies for antiretroviral production training. Kaiser Daily HIV/AIDS Report, 31 May 2007. www.kaisernetwork.org /daily_reports/print_report.cfm?DR_ID=45 253\&dr_cat...

135. Abuja Declaration on HIV/AIDS, tuberculosis and other related infectious diseases. 27 April 2001. www.uneca.org/adf2000/Abuja\%20Declara tion.htm

136. Gleneagles Implementation Plan for Africa. July 2007 update. www.dfid.gov.uk/g8/milestones.asp

137. Report of the Special Summit of African Union on HIV/AIDS, TB and Malaria. Abuja, May 2-4, 2006. www.africa-union.org/root/au/ conferences/past $/ 2006 / \mathrm{may} /$ summit/doc/en ISP_PRC_ATM21_concept_paper.pdf 
138. Presentation of the UNITAID Initiative. French Mission to the United Nations, 20 September 2006

www.franceonu.org/article.php3?id_article= 1243

139. Clinton Foundation announces deal with drug companies to reduce cost of antiretrovirals in developing countries. Kaiser Daily HIV/AIDS Report, 9 May 2007.

www.kaisernetwork.org/Daily_reports/print _report.cfm?DR_ID=44782\&dr_cat

140. Former president Clinton to launch hospital project in Malawi, promote HIV/AIDS program in Zambia. Kaiser Daily HIV/AIDS Report, 20 July 2007. www.kaisernetwork.org/Daily_reports/print _report.cfm?DR_ID=46352\&dr_cat

141. Members OK amendment to make health flexibility permanent. 6 December 2005. www.wto.org/english/news_e/pres05_e/pr4 26_e.htm
142. Countries accepting amendment of the TRIPS agreement. www.wto.org/english/tratop_e/trips_e/amen dment_e.htm

143. Trips Council extends public health deadline. ICTSD Bridges, 11(37) (2007\#). www.ictsd.org/weekly/07-10-31/story2.htm

\section{Affiliations}

- Daniele Dionisio, Coordinator

Access to Drugs: International Policies - CLIA (Italian Network for International Fight against AIDS), Member, Working Group on AIDS (Decentralized Cooperation of Tuscany Region), and,

Director, Infectious Diseases Division, Pistoia Hospital, Piazza Giovanni XXIII 1, Pistoia, Italy

Tel.: +390573 352 324;

Fax: +390573 352309 ;

d.dionisio@usl3.toscana.it
- Arun Kumar Khanna, Executive Director Emcure Pharmaceuticals Ltd, Member of Board of Directors, Dapodi, Pune, India Arun@emcure.co.in

- Stavros Nicolaou, Head of Strategic Trade Aspen Pharmacare Holdings, Sandton, South Africa snicolaou@aspenpharma.com

- Vijaya Raghavan, Senior Director Ranbaxy Laboratories Ltd, Intellectual Property Cell, Gurgaon, Haryana, India Vijaya.raghavan@ranbaxy.com

- Sandeep Juneja, Director Ranbaxy Laboratories Ltd, HIV \& Malaria Projects, Gurgaon, Haryana, India sandeep.juneja@ranbaxy.com

- Aloka Sengupta, Vice President Strides Arcolab Ltd, AIDS, Tuberculosis \& Malaria, Bangalore, India aloka.sengupta@stridesarco.com

- Daniela Messeri, Assistant MD Pistoia Hospital, Division of Infectious Diseases, Pistoia, Italy aledanibatibeba@hotmail.com 